Original Article

\title{
Effects of 12-week lumbar stabilization exercise and sling exercise on lumbosacral region angle, lumbar muscle strength, and pain scale of patients with chronic low back pain
}

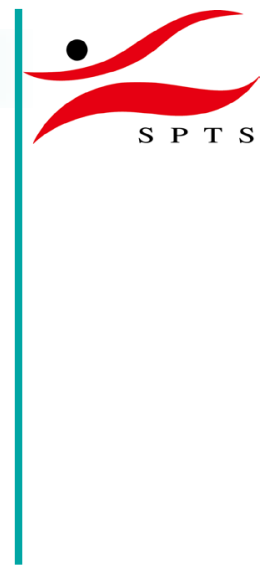

\author{
Kwang-Jun Ko, $\mathrm{PhD}^{1)}$, Gi-Chul Ha, MS ${ }^{1)}$, Young-Sook Yook, $\mathrm{PhD}^{2)}$, SeOl-Jung Kang, PhD ${ }^{3 *}$ \\ 1) Department of Sports Medicine, National Fitness Center, Republic of Korea \\ 2) Department of Exercise Rehabilitation Welfare, Sungshin Women's University, Republic of Korea \\ 3) Department of Physical Education, Changwon National University: 20 Changwondaehak-ro, \\ Uichang-gu, Changwon-si, Gyeongsangnam-do, Republic of Korea
}

\begin{abstract}
Purpose] The purpose of this study is to investigate the effects of lumbar stabilization exercise and sling exercise on lumbosacral region angle, lumbar muscle strength, pain scale of patients with chronic low back pain. [Subjects and Methods] The subjects of this study were 29 chronic low back pain patient women who were selected among participants in exercise class at K Region Health Promotion Center in South Korea and were randomly assigned to the lumbar stabilization exercise group $(n=10)$, sling exercise group $(n=10)$, and the control group $(n=9)$. Both lumbar stabilization and sling exercise programs were executed for 60 minutes, three times a week, for 12 weeks. Before and after exercise we measured lumbosacral region angle (lumbar lordosis angle, lumbosacral angle, sacral inclination angle), lumbar muscle strength, and pain scale in all subjects. Two-way analysis of variance was conducted to analyze experimental data. In order to analyze the interaction effect, we conducted paired t-test before and after treatment. [Results] Lumbar stabilization exercise group and sling exercises group did not affect lumbar lordosis angle, lumbosacral angle and sacral inclination angle. Whereas the lumbar flexion muscle strength and lumbar extension muscle strength significantly increased in the lumbar stabilization exercise group and sling exercise group. The flexibility increased in the lumbar stabilization exercise group and sling exercise group. The pain scale decreased in the lumbar stabilization exercise group and sling exercise group. [Conclusion] Both lumbar stabilization exercise and sling exercises are useful therapeutic approaches to chronic back pain.

Key words: Lumbar stabilization exercise, Sling exercise, Chronic back pain
\end{abstract}

(This article was submitted Aug. 9, 2017, and was accepted Oct. 4, 2017)

\section{INTRODUCTION}

Back pain is a common musculoskeletal ailment related to vertebral malalignment ${ }^{1)}$. To distribute the body's load during orthograde movement and other daily activities, human vertebrae form normal curvatures from the neck to the pelvis. However, inclination or declination of sagittal lumbar lordosis can lead to excessive load being applied on vertebral joints and intervertebral discs, resulting in nerve root compression, disc degeneration, and inflammation of joint capsules ${ }^{2-4)}$. Christie et al. ${ }^{5)}$ reported increased lumbosacral angles in patients with chronic back pain. In addition, more than $80 \%$ of patients with back pain have limited range of motion, lumbar flexion, flexor muscle weakening, and imbalance of muscle strength ${ }^{6,7)}$. Research findings have also verified the association between chronic back pain and vertebral instability caused by lumbar muscular atrophy ${ }^{10)}$.

*Corresponding author. Seol-Jung Kang (E-mail: sjkang803@hanmail.net)

(C2018 The Society of Physical Therapy Science. Published by IPEC Inc.

This is an open-access article distributed under the terms of the Creative Commons Attribution Non-Commercial No Derivatives (by-nc-nd) License. (CC-BY-NC-ND 4.0: https://creativecommons.org/licenses/by-nc-nd/4.0/) 
Table 1. Physical characteristics of subjects

\begin{tabular}{lccc}
\hline Group & $\begin{array}{c}\text { Lumbar stabilization exercise } \\
(\mathrm{n}=10)\end{array}$ & $\begin{array}{c}\text { Sling exercise } \\
(\mathrm{n}=10)\end{array}$ & $\begin{array}{c}\text { Control } \\
(\mathrm{n}=9)\end{array}$ \\
\hline Age $(\mathrm{yrs})$ & $43.1 \pm 3.7$ & $43.6 \pm 4.5$ & $41.3 \pm 3.8$ \\
Height $(\mathrm{cm})$ & $161.6 \pm 3.4$ & $160.0 \pm 3.8$ & $161.1 \pm 4.2$ \\
Weight $(\mathrm{kg})$ & $57.5 \pm 6.1$ & $58.7 \pm 5.0$ & $56.2 \pm 4.6$ \\
Body mass index $\left(\mathrm{kg} / \mathrm{cm}^{2}\right)$ & $21.9 \pm 1.6$ & $22.9 \pm 1.8$ & $21.6 \pm 1.2$ \\
\hline
\end{tabular}

Value are Mean \pm SD.

Therefore, strengthening lumbar muscles and increasing lumbar flexibility are important objectives of lumber pain treatment ${ }^{8)}$. Exercise can help strengthen muscles and maintain asymptomatic lumbar lordosis ${ }^{9}$. Specifically, lumbar stabilization exercises can provide therapeutic benefits in the treatment of chronic back pain ${ }^{11)}$ through the adjustment of vertebral segments and an increase in dynamic stability and lumbar muscle strength ${ }^{12,13)}$.

Sling exercise, which is based on the concept of lumbar stabilization, is also used to treat back pain. Sling exercise is a closed-chain load-bearing exercise using a suspension that has been reported to improve lumbar curvature and muscle imbalance ${ }^{14-16)}$.

But, there are no studies that compare the clinical outcomes of lumbar stabilization exercises with the outcomes of sling exercises. Thus, this study compares the effects of each type of exercise on lumbosacral region angle, lumbar muscle strength, and pain scale in patients with chronic back pain.

\section{SUBJECTS AND METHODS}

At the National Health Center in Seoul, 29 patients met the study criteria and consented to participate in our study. These were patients with chronic back pain in their age 30-40s who did not require surgical treatments following X-ray and CT (computed tomography) scans. The enrolled patients were randomly assigned to a lumbar stabilization exercise group ( $\mathrm{n}=10)$, a sling exercise group $(\mathrm{n}=10)$, and a control group $(\mathrm{n}=9)$. The study was conducted in compliance with the Declaration of Helsinki, and all patients were given complete information about our investigation. The patients consented to the collection and utilization of personal information. Table 1 summarizes patient characteristics.

Lumbar lordosis angle, lumbosacral angle, and sacral slope were measured on simple X-ray images of the lateral view of the lumbar region. Angles were measured by using a ViewRex PACS (Techheim, Korea) system. Lumbar lordosis angle was measured at the intersection between a line extending from the upper plate of L1 and another extending from the lower plate of L5. Lumbosacral angle was measured at the intersection between a line extending from the lower plate of L5 and another extending from the upper plate of the sacrum. Sacral slope was measured at the intersection between a line extending from the upper and lower plates of the sacrum.

The lumbar muscle strength test was performed using the Biodex 3.0 (Biodex Medical Systems, Shirley, NY, USA), an isokinetic muscle strength analyzer, to measure the muscle strength involved in lumbar flexion and extension. Before the lumbar muscle strength test, subjects were given 10 minutes for the stretching and warm-up exercise, and the actual test was performed after they were familiar with the lumbar flexion and extension test method. Lumbar flexor and extensor muscles were measured five times at $30^{\circ} \mathrm{sec}$, and the maximum value from the five measurements was recorded.

Flexibility test was performed by bending the upper body forward. After sufficient stretching prior to the flexibility test, the subjects sat on the examination table and bent the upper body forward as much as possible with the legs fully extended. This motion was performed and measured twice, and the maximum value from the two measurements was recorded. The maximum value was recorded in $\mathrm{cm}$.

Pain scale were subjectively assessed by using questionnaires, where the participants could rate their pain from 0 for "no pain" to 10 for "severe pain" depending on their perceived levels of pain and disability.

Exercise programs were executed for 60 minutes, three times a week for 12 weeks. The program included 10 minutes of warm-up, 40 minutes of main exercise, and 10 minutes of cool-down. Warm up exercises consisted of walking and stretching, and cool-down exercises consisted of stretching. The main exercise consisted of eight kinds of workouts; 1) sit up, 2) superman exercise, 3) quadruped arm \& leg raise, 4) squat, 5) lower body fixation plank (surface or sling), 6) upper body fixation plank (surface or sling), 7) side plank (surface or sling), and 8) hip bridge (surface or sling). Both lumbar stabilization and sling exercise groups performed 1)-4) on the floor. The lumbar stabilization group performed 5)-8) on the floor, and the sling exercise group performed the same exercises using slings. Both groups performed three sets of each exercise with 10 movements per set.

The data in this study were analyzed using SPSS (Version, 18). Two-way ANOVA by repeated measure was performed to test interaction effects on the measured variables between groups and measurement time. Statistical significance was set at $\mathrm{p}<0.05$. 
Table 2. Change of lumbosacral region angle

\begin{tabular}{llcc}
\hline \multicolumn{1}{c}{ Variability } & \multicolumn{1}{c}{ Group } & Pre & Post \\
\hline Lumbar lordosis angle $\left(^{\circ}\right)$ & Lumbar stabilization exercise & $40.0 \pm 1.5$ & $39.7 \pm 1.6$ \\
& Sling exercise & $38.9 \pm 2.1$ & $38.7 \pm 2.1$ \\
& Control & $40.0 \pm 2.4$ & $40.1 \pm 2.4$ \\
\hline Lumbosacral angle $\left(^{\circ}\right)$ & Lumbar stabilization exercise & $13.0 \pm 1.0$ & $12.8 \pm 1.2$ \\
& Sling exercise & $13.5 \pm 1.8$ & $13.5 \pm 1.8$ \\
& Control & $13.1 \pm 1.7$ & $13.1 \pm 1.7$ \\
\hline Sacral inclination angle $\left(^{\circ}\right)$ & Lumbar stabilization exercise & $39.4 \pm 1.8$ & $38.9 \pm 1.8$ \\
& Sling exercise & $38.5 \pm 2.2$ & $38.7 \pm 2.1$ \\
& Control & $39.7 \pm 1.5$ & $39.4 \pm 1.7$ \\
\hline
\end{tabular}

Value are Mean \pm SD.

Table 3. Change of lumbar muscle strength and flexibility

\begin{tabular}{llcc}
\hline \multicolumn{1}{c}{ Variability } & \multicolumn{1}{c}{ Group } & Pre & Post \\
\hline Lumbar flexion muscle (Nm) & Lumbar stabilization exercise & $109.7 \pm 9.8$ & $116.6 \pm 8.6^{* * *}$ \\
& Sling exercise & $107.9 \pm 7.4$ & $117.5 \pm 8.6^{*}$ \\
& Exercise & $105.4 \pm 11.1$ & $106.2 \pm 12.4$ \\
\hline Lumbar extension muscle (Nm) & Lumbar stabilization exercise & $172.0 \pm 14.1$ & $184.0 \pm 17.2^{* * *}$ \\
& Sling exercise & $164.8 \pm 14.8$ & $188.4 \pm 18.2^{* * *}$ \\
& Control & $169.6 \pm 14.9$ & $171.2 \pm 26.1$ \\
\hline Flexibility (cm) & Lumbar stabilization exercise & $9.8 \pm 6.0$ & $11.3 \pm 6.0^{* *}$ \\
& Sling exercise & $8.5 \pm 6.6$ & $11.5 \pm 5.6^{*}$ \\
& Control & $8.7 \pm 5.7$ & $9.1 \pm 5.7$ \\
\hline
\end{tabular}

Value are Mean \pm SD, paired t-test: ${ }^{*} \mathrm{p}<0.05,{ }^{* *} \mathrm{p}<0.01,{ }^{* * *} \mathrm{p}<0.001$.

Table 4. Change of pain scale

\begin{tabular}{clcl}
\hline \multicolumn{1}{c}{ Variability } & \multicolumn{1}{c}{ Group } & Pre & \multicolumn{1}{c}{ Post } \\
\hline Pain scale (score) & Lumbar stabilization exercise & $5.5 \pm 1.3$ & $4.0 \pm 0.6^{* *}$ \\
& Sling exercise & $5.3 \pm 1.3$ & $3.8 \pm 1.0^{* *}$ \\
& Control & $5.2 \pm 2.1$ & $5.1 \pm 1.8$ \\
\hline
\end{tabular}

Value are Mean $\pm \mathrm{SD}$, paired t-test; $* * \mathrm{p}<0.01$

\section{RESULTS}

As shown in Table 2, the lumbar lordosis angle did not have any interaction effects between groups and treatment. The lumbosacral angle did not have any interaction effects between groups and treatment. The sacral inclination angle did not have any interaction effects between groups and treatment. As shown in Table 3, lumbar flexion muscle strength showed interaction effects between group and treatment $(\mathrm{p}<0.05)$. Interaction effect analysis results indicated that the lumbar stabilization exercise group and sling exercise group showed a significant increase from pre- to post-exercise respectively $(p<0.001$, $\mathrm{p}<0.5$ ), whereas the control group did not have a significant difference in the lumbar flexion muscle strength between these periods.

Lumbar extension muscle strength showed interaction effects between group and treatment $(\mathrm{p}<0.01)$. Interaction effect analysis results indicated that the lumbar stabilization exercise group and sling exercise group showed a significant increase from pre- to post- exercise respectively $(\mathrm{p}<0.001, \mathrm{p}<0.001)$, whereas the control group did not have a significant difference in the lumbar extension muscle strength between these periods.

Flexibility showed interaction effects between group and treatment $(\mathrm{p}<0.001)$. Interaction effect analysis results indicated that the lumbar stabilization exercise group and sling exercise group showed a significant increased from pre- to post-exercise respectively $(\mathrm{p}<0.1, \mathrm{p}<0.5)$, whereas the control group did not have a significant difference in the flexibility between these periods.

As shown in Table 4, pain scale showed interaction effects between group and treatment $(\mathrm{p}<0.05)$. Interaction effect analysis results indicated that the lumbar stabilization exercise group and sling exercise group showed a significant decrease from pre- to post-exercise respectively $(\mathrm{p}<0.01, \mathrm{p}<0.01$ ), whereas the control group did not have a significant difference in the flexibility between these periods. 


\section{DISCUSSION}

This study examined the effects of lumbar stabilization and sling exercises on lumbosacral region angle, lumbar muscle strength, and pain score of patients with chronic back pain. Neither type of exercise had significant effects on lumbar lordosis, lumbosacral angle or sacral slope; however, both types of exercise increased lumbar muscle strength and reduced pain scores.

Low back pain is a clinically common musculoskeletal ailment that can interfere with occupational and daily activities. The spine, which is closely associated with lumbar pain, is the central pillar of the body. The sagittal balance of the spine is formed by cervical lordosis, thoracic kyphosis, and lumbar lordosis. Changes in the lumbar curvature increase dynamic loads on the lumbar area, often inducing lumbar pain ${ }^{17)}$. Lumbar lordosis angle is an index of lumbar lordosis and structural stability. The lumbosacral angle is another important measure that accounts for two-thirds of lumbar lordosis ${ }^{18)}$.

Previous studies have reported no significant difference in the lumbar lordosis angle between patients with chronic back pain and those without, while others have reported increased lumbar lordosis angles in the former ${ }^{5,19,20)}$. In our study of low back pain patients, neither lumbar stabilization exercises nor sling exercises had a significant effect on the lumbar lordosis angle, lumbosacral angle, or sacral slope compared to pre-intervention measurements. Similarly, in a study by Oh et al. ${ }^{21)}$, lumbar stabilization exercise did not significantly affect the lumbar lordosis angle in women in their 20-30s. Therefore, our findings are consistent with those from other studies in that lumbar stabilization and sling exercises did not affect sagittal lumbar lordosis in patients with chronic back pain. However, research attempting to establish standardized and normal values of lumbar lordosis has been inconclusive, as lumbar lordosis is affected by several variables, including age, gender, vertebral disease and related biomechanical structures ${ }^{22}$. Therefore, a systemic evaluation of the effects of exercise on lumbar lordosis using clinical findings is necessary.

Chronic back pain is associated with the weakening of the lumbar extensor and flexor muscles, muscle imbalances ${ }^{23)}$, and especially lumbar instability. Treatment of chronic back pain thus requires lumbar stabilization exercises, which strengthen the lumbar muscles and increase flexibility ${ }^{24)}$. Previous studies have reported successful increases in muscle strength from such exercises ${ }^{10,25}$. Sling exercises have also been reported to increase lumbar muscle strength in patients with chronic back pain $^{26)}$. In our study, lumbar stabilization and sling exercises significantly increased lumbar muscle strength and flexibility in patients with chronic back pain. Therefore, our findings underscore the therapeutic benefits of these exercises in increasing lumbar muscle strength and the range of motion of the lumbar joints, and ultimately regaining lumbar stability.

Among patients for whom the main symptom is chronic back pain, pain reduction is an important objective of treatment. In a previous study, lumbar stabilization exercise alleviated pain in patients with chronic back pain ${ }^{27}$ ). Likewise, lumbar stabilization and sling exercises were found to reduce lumbar disability scores in previous studies ${ }^{26,28)}$. Our findings were similar: lumbar stabilization and sling exercises significantly reduced the subjective pain score of patients with chronic back pain. Therefore, it seems that both the lumbar stabilization exercise and the sling exercise lower the stress on the spinal structure. As a result, it can be seen that lumbar stability, lumbar muscle strength, increased range of motion and reduction of pain are effective in low back pain patients.

In conclusion, 12 weeks of lumbar stabilization and sling exercises did not affect lumbosacral region angle in patients with chronic back pain; however, the exercises effectively increased lumbar muscle strength and flexibility and reduced pain scores, likely by reducing the load on the spine. Therefore, both lumbar stabilization exercise and sling exercises are useful therapeutic approaches to chronic back pain.

\section{REFERENCES}

1) Manek NJ, MacGregor AJ: Epidemiology of back disorders: prevalence, risk factors, and prognosis. Curr Opin Rheumatol, 2005, 17: 134-140. [Medline]

2) Barrey C, Jund J, Noseda O, et al.: Sagittal balance of the pelvis-spine complex and lumbar degenerative diseases. A comparative study about 85 cases. Eur Spine J, 2007, 16: 1459-1467. [Medline] [CrossRef]

3) Ergün T, Lakadamyalı H, Sahin MS: The relation between sagittal morphology of the lumbosacral spine and the degree of lumbar intervertebral disc degeneration. Acta Orthop Traumatol Turc, 2010, 44: 293-299. [Medline] [CrossRef]

4) Rajnics P, Templier A, Skalli W, et al.: The importance of spinopelvic parameters in patients with lumbar disc lesions. Int Orthop, 2002, 26: 104-108. [Medline] [CrossRef]

5) Christie HJ, Kumar S, Warren SA: Postural aberrations in low back pain. Arch Phys Med Rehabil, 1995, 76: 218-224. [Medline] [CrossRef]

6) Elnaggar IM, Nordin M, Sheikhzadeh A, et al.: Effects of spinal flexion and extension exercises on low-back pain and spinal mobility in chronic mechanical low-back pain patients. Spine, 1991, 16: 967-972. [Medline] [CrossRef]

7) Langrana NA, Lee CK, Alexander H, et al.: Quantitative assessment of back strength using isokinetic testing. Spine, 1984, 9: 287-290. [Medline] [CrossRef]

8) Handa N, Yamamoto H, Tani T, et al.: The effect of trunk muscle exercises in patients over 40 years of age with chronic low back pain. J Orthop Sci, 2000, 5: 210-216. [Medline] [CrossRef]

9) Faas A: Exercises: which ones are worth trying, for which patients, and when? Spine, 1996, 21: 2874-2878, discussion 2878-2879. [Medline] [CrossRef]

10) França FR, Burke TN, Hanada ES, et al.: Segmental stabilization and muscular strengthening in chronic low back pain: a comparative study. Clinics (Sao Paulo), 2010, 65: 1013-1017. [Medline] [CrossRef]

11) Panjabi MM: Clinical spinal instability and low back pain. J Electromyogr Kinesiol, 2003, 13: 371-379. [Medline] [CrossRef] 
12) Arokoski JP, Valta T, Kankaanpää M, et al.: Activation of lumbar paraspinal and abdominal muscles during therapeutic exercises in chronic low back pain patients. Arch Phys Med Rehabil, 2004, 85: 823-832. [Medline] [CrossRef]

13) Rasmussen-Barr E, Nilsson-Wikmar L, Arvidsson I: Stabilizing training compared with manual treatment in sub-acute and chronic low-back pain. Man Ther, 2003, 8: 233-241. [Medline] [CrossRef]

14) Haynes W: Core stability and the unstable platform device. J Bodyw Mov Ther, 2004, 8: 88-103. [CrossRef]

15) Lee JS, Yang SH, Koog YH, et al.: Effectiveness of sling exercise for chronic low back pain: a systematic review. J Phys Ther Sci, 2014, 26: 1301-1306. [Medline] [CrossRef]

16) Pederson JS, Kirkesola G, Magnussen R, et al: Sling exercise training improves balance, Kicking velocity and torso stabilization strength in elite soccer players. Med Sci in sport Exer, 2006, 38: 243-250. [CrossRef]

17) Nies N, Sinnott PL: Variations in balance and body sway in middle-aged adults. Subjects with healthy backs compared with subjects with low-back dysfunction. Spine, 1991, 16: 325-330. [Medline] [CrossRef]

18) Jackson RP, McManus AC: Radiographic analysis of sagittal plane alignment and balance in standing volunteers and patients with low back pain matched for age, sex, and size. A prospective controlled clinical study. Spine, 1994, 19: 1611-1618. [Medline] [CrossRef]

19) Evcik D, Yücel A: Lumbar lordosis in acute and chronic low back pain patients. Rheumatol Int, 2003, 23: 163-165. [Medline] [CrossRef]

20) Sluming VA, Scutt ND: The role of imaging in the diagnosis of postural disorders related to low back pain. Sports Med, 1994, 18: 281-291. [Medline] [CrossRef]

21) Oh JS, Choi DG, Kim YS: The effect of lumbar stability exercise program on sedentary life female, lumbosacral region angle, muscular strength, physical fitness and pain scale. Korean J Sports Med, 2017, 35: 15-24. [CrossRef]

22) Schenkman M, Shipp KM, Chandler J, et al.: Relationships between mobility of axial structures and physical performance. Phys Ther, 1996, 76: 276-285. [Medline] [CrossRef]

23) Mayer T, Gatchel R, Betancur J, et al.: Trunk muscle endurance measurement. Isometric contrasted to isokinetic testing in normal subjects. Spine, 1995, 20: 920-926, discussion 926-927. [Medline] [CrossRef]

24) O'Sullivan PB, Burnett A, Floyd AN, et al.: Lumbar repositioning deficit in a specific low back pain population. Spine, 2003, 28: 1074-1079. [Medline] [CrossRef]

25) O'Sullivan PB, Phyty GD, Twomey LT, et al.: Evaluation of specific stabilizing exercise in the treatment of chronic low back pain with radiologic diagnosis of spondylolysis or spondylolisthesis. Spine, 1997, 22: 2959-2967. [Medline] [CrossRef]

26) Yoo YD, Lee YS: The effect of core stabilization exercises using a sling on pain and muscle strength of patients with chronic low back pain. J Phys Ther Sci, 2012, 24: 671-674. [CrossRef]

27) Heo MY, Kim K, Hur BY, et al.: The effect of lumbar stabilization exercises and thoracic mobilization and exercises on chronic low back pain patients. J Phys Ther Sci, 2015, 27: 3843-3846. [Medline] [CrossRef]

28) Hicks GE, Fritz JM, Delitto A, et al.: Preliminary development of a clinical prediction rule for determining which patients with low back pain will respond to a stabilization exercise program. Arch Phys Med Rehabil, 2005, 86: 1753-1762. [Medline] [CrossRef] 